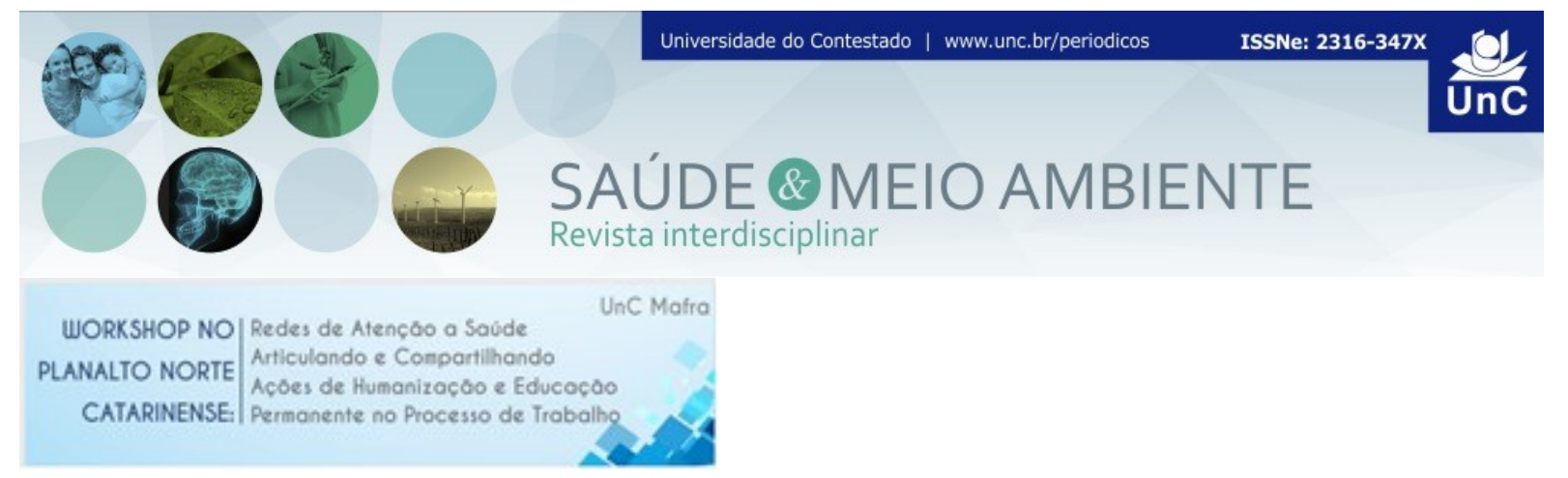

\title{
EMPODERANDO AS AGENTES COMUNITÁRIAS DE SAÚDE, NA DETECÇÃO DO HIV E SÍFILIS
}

\author{
Francesli Pereira ${ }^{1}$ \\ Ariane Woehl ${ }^{2}$ \\ Luciana Maria Mazon ${ }^{3}$
}

\section{RESUMO}

INTRODUÇÃO: Através dos Indicadores Epidemiológicos, observamos o aumento dos casos de Infecção por Sífilis e HIV, em nossos cenários sociais. Sinalizando há necessidade significativa de sensibilização ao assunto a partir da Atenção Básica, como um recurso inicial de discussão, para fomentar o acolhimento diferenciado, dentro das Unidades Básicas de Saúde. Gouvea (2015) aponta que é preciso agir de forma intensificada contra as Infecções Sexualmente Transmissíveis (IST), pois caso contrário, corremos o risco de testemunharmos um recrudescimento da epidemia dessas doenças. Considerando que o Agente Comunitário de Saúde (ACS), é o trabalhador dentro do Sistema Único de Saúde, que tem o primeiro contato com a comunidade do território e considerando ainda que esta condição pode permitir o rápido acesso a informações da população em relação aos IST foi proposta a capacitação "IST com ênfase no HIVIAIDS e Sífilis, exclusiva para o ACS". OBJETIVOS: Ampliar o conhecimento dos ACS com relação às ISTs; instrumentalizar os ACS para que reapliquem as discussões com suas equipes de trabalho, ações de prevenção e acompanhamento dos casos notificados; ampliar as discussões com relação ao HIVIAIDS e Sífilis, desmitificando preconceitos. RELATO DE EXPERIÊNCIA: A capacitação ocorreu no ano de 2016. Foram realizados quatro encontros de capacitação, cada um deles com 33 ACS, totalizando ao final 135 ACS do município de Mafra que receberam o treinamento. Cada encontro teve carga horária de $8 \mathrm{~h}$. Durante a capacitação foram utilizados diferentes recursos didáticos para explorar as temáticas. Os temas abordados foram: 1-Conceituação AIDS e Sífilis; 2-Indicadores Epidemiológicos; 3-Tratamento e orientações de acompanhamento; 4Mitos e Tabus, frente ás DSTs; 5-Ações de Prevenção na Atenção Básica, sendo tanto com aportes teóricos, como práticas que melhor explorassem os conteúdos propostos. Após um ano foram avaliados o número de testes rápidos realizados para a detecção das IST (HIV, Sífilis) e o número de detecção de casos de HIV e Sífilis.

\footnotetext{
${ }^{1}$ Enfermeira. Especialista em Obstetrícia. Santa Catarina. Brasil. E-mail: franceslipph@yahoo.com.br ${ }^{2}$ Assistente Social. Especialista em Gerenciamento de Unidades Básicas de Saúde; Especialista em Impactos da Violência na Saúde e em Gestão em Saúde Pública; Especialista em Gestão em Saúde Pública. Santa Catarina. Brasil. E-mail. arianewoehl@gmail.com

${ }^{3}$ Enfermeira. Doutoranda em Saúde Coletiva. Membro NEP-Mafra-SC. Santa Catarina. Brasil. E-mail. lucimazon@hotmail.com
} 
RESULTADOS: Um ano após a capacitação verificou-se que a procura pela realização de testes rápidos foi ampliada em todas as unidades de saúde. O número de teste rápidos realizados aumentou $50 \%$ no município comparado ao ano anterior a capacitação. O número crescente na realização de testes acompanhou também a ampliação no número de casos diagnosticados para sífilis e HIV. CONCLUSÕES: Foi observado o aumento significativo da oferta das testagens rápidas nas Unidades Básicas de Saúde, a partir da Capacitação desenvolvida com as ACS do Município de Mafra, bem como a busca pelos métodos de prevenção como preservativos masculinos e femininos.

Palavras-Chave: Agente Comunitário de Saúde. Prevenção. Doenças sexualmente transmissíveis.

\section{REFERÊNCIAS}

GOUVEA, G. Um mundo sem AIDS, É possível? Revista Radis, n. 156, set., p. 35, 2015.

Resumo recebido em: 12/12/2017

Resumo aprovado em: 17/12/2017

Resumo publicado em: 20/12/2017 